\title{
Lithostratigraphic Characterization of the Subsurface in Ologbo Community using Wenner-Schlumberger Electrode Configuration of Electrical Resistivity Method
}

\author{
Egbo Okechukwu. ${ }^{1}$ and Bright C. Abanum. ${ }^{2}$ \\ ${ }^{1}$ Department of Physics, Ambrose Alli University, Ekpoma, Nigeria \\ ${ }^{2}$ Department of Physics, University of Benin, Benin City, Nigeria
}

\begin{abstract}
Wenner-Schlumberger electrode configuration of the electrical resistivity method of geophysical investigation was carried out in Ologbo Community Edo State Nigeria in order to characterize the subsurface geology in this location. The Petrozenith earth resistivity meter was used to measure the resistance offered by the subsurface in two different locations in this geophysical investigation. Sixty (60) Wenner-Schlumberger soundings were carried out in each of the areas. Data were collected and processed using Res2dinv software which produced an inverse model resistivity section which is the true resistivity of the subsurface and this was used to deduce the geological characteristics of the surveyed depth range. Interpretation of the inverse model resistivity section using knowledge of the geology of the study area and standard electrical resistivity of earth materials available in the literature indicates the presence of clayey sand, lateritic clay, laterite, sand and sandstone as the make-up of the subsurface geology of the study area.
\end{abstract}

Keywords: Wenner-Schlumberger, Geoelectric, lithology, Lateritic clay.

\section{INTRODUCTION}

This study was carried out to map out subsurface lithostratigraphic characteristics in the studied location. Subsurface materials such as rocks, minerals and water occur naturally within the earth's surface and establish the raw materials upon which our global society exists and thrives. The geologic makeup of an area is of necessity when considering construction of roads, buildings, and dams for hydropower generation. For example, laterite as a rock type is of immense economic importance. We see the use of laterite as a base course in place of stone in construction of low-density roads. Laterites are widely used to build blocks, build roads, as aquifers in water supply, water treatment etc [1]. Another important economic rock material is the clay mineral. Clay minerals are of great significance among the world's most important and useful industrial mineral. In agriculture, clay minerals are a major component of soil and determinant of soil properties. The clay minerals are important in construction where they are major constituents in bricks and tiles [2]. Even in prehistoric times, sandstone was used for domestic construction and house wares and also used for artistic purposes to create ornamental fountains and statues. In construction, sand is an integral part of concrete, it is used for growing crops, and it is glued to paper to make sandpaper. Previous studies done in this area have been able to show the presence of clay, laterite, sand, and gravel. Therefore, there is a need to investigate a greater depth in search for such valuable materials.

One of the many direct ways in which geophysical investigation aids the general economy is in the delineation of subsurface lithology or rock types which give rise to oil/ mineral, gas and other valuable products of different kinds [3].

Abanum C. Bright worked on determination of groundwater potential using two - dimensional geoelectrical imaging in ologbo of Edo state Nigeria, where he observed that the area is predominantly sand with sparse deposit of clay and hence the studied area may hold good prospect for groundwater in view of the probable thick aquifer layer [4].

The geoelectric method of geophysical investigation utilizes the electrical properties of the subsurface materials to differentiate the subsurface into geoelectric layers and sections. Geoelectric resistivity is one of the variables which are the physical properties of the rock layer below the subsurface. Rock resistivity data can be used to develop a model of subsurface and stratigraphic structures in terms of electrical properties. Geoelectric resistivity depends on lithology, air content, porosity and pore ion concentration [5]. 
International Journal of Advances in Scientific Research and Engineering (ijasre), Vol 6 (6), June -2020

\section{LOCAL GEOLOGIC SETTINGS}

Ologbo community is located in Ikpoba-Okha Local government area of Edo State. The community is essentially rural and its geographical coordinates are $6^{\circ} 3^{\prime} 0^{\prime \prime}$ North and $5^{\circ} 40^{\prime} 0^{\prime \prime}$ East. The geology of this research area is characterized by deposits laid during tertiary and cretaceous periods. The area is underlain by sedimentary rock constituting part of the Benin Formation which is made up of over $90 \%$ massive, porous, coarse sand with clay/shale inter-beds having high groundwater retention capacity [6]. Soil particles vary from coarse grained to fine grained in some areas, poorly sorted, sub-angular to well-rounded particles with ignite streaks and fragment.

Ologbo Formation is aquiferous in nature due to its very low percentage of shaly layers having a depth of about $2445 \mathrm{~m}$ with no overpressure [7]. This community falls within the well-known rainforest belt of Nigeria, with dual seasons; wet season (March to October) and the dry season period (November to March) the following year.

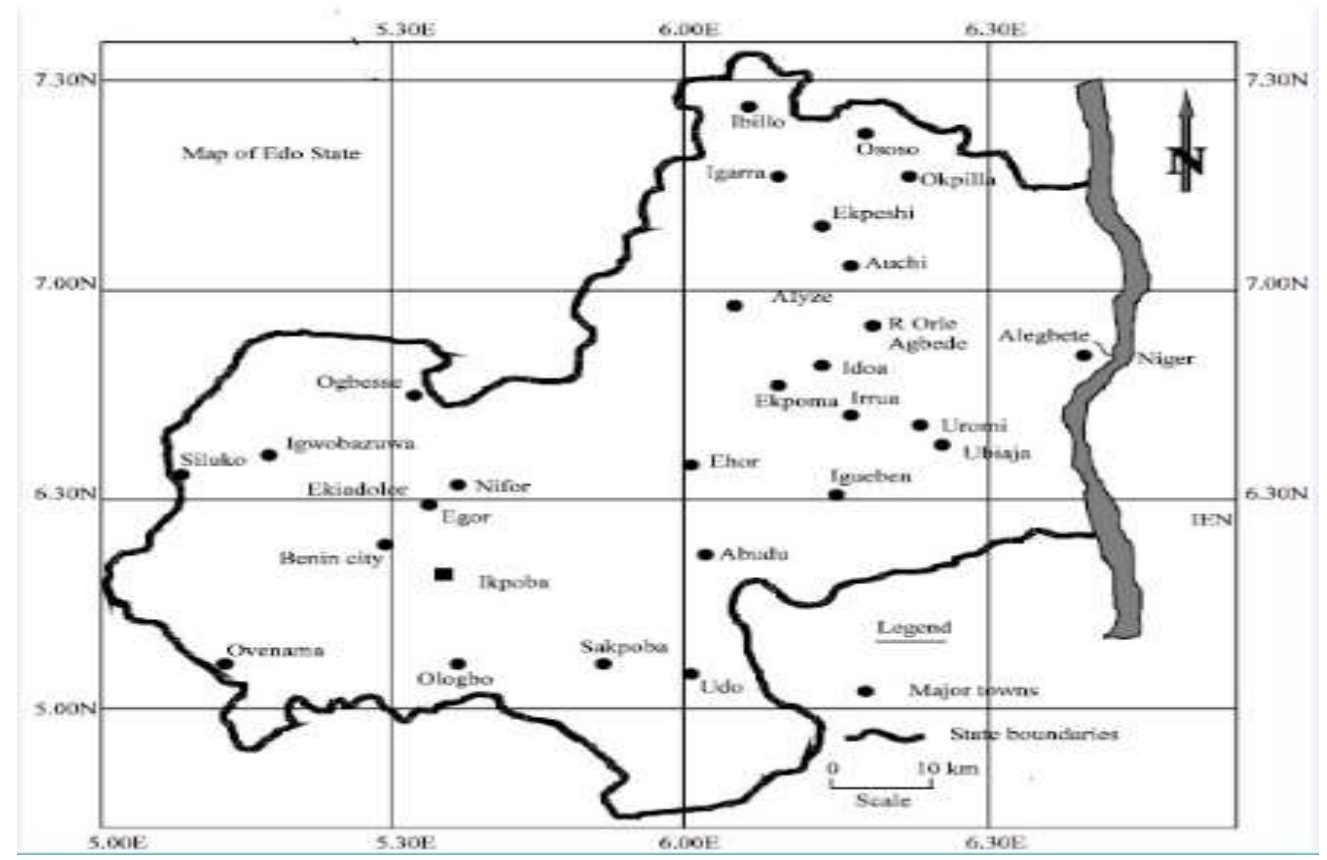

Figure 1: Map of Edo State Showing Ologbo [8].

\subsection{Theory}

The geoelectrical method of geophysical investigation is capable of locating both low and high resistive formations, therefore it is an important tool for characterizing subsurface lithology [9]. Due to the inhomogeneity of soils, the resistivity of soils varies with depth. Soil resistivity is a complicated function of permeability, ionic content of the pores fluids, clay mineralization and porosity [10].

Geoelectrical investigation is carried out by measuring the electrical potential (V) resulting from current input (I) into the ground with the purpose of achieving information on the resistivity structure in the ground. The resistance is obtained using Ohm's law

$$
\boldsymbol{R}=\frac{\boldsymbol{V}}{\boldsymbol{I}}
$$

And then the apparent resistivity is computed using the equation,

$\rho_{a}=K R$

Where $\mathrm{K}$ is the geometric factor which depends on the arrangement of the four electrodes [11]. The electrical resistivity method involves the measurement of the apparent resistivity of soils and rock as a function of depth. It is expressed in ohm-meters [12]. 


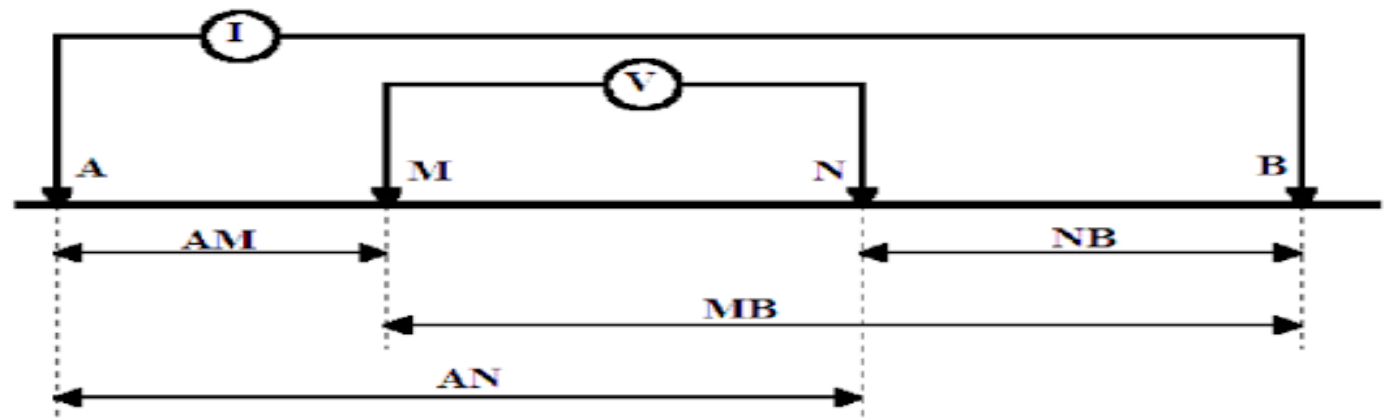

Figure 2: Generalized electrode configuration for resistivity measurement.

Consider a single point electrode, located on the boundary of a semi-infinite, electrically homogenous medium, which represents a fictitious homogenous earth. If the electrode carries a current I, measured in amperes (A), the potential difference (V) across a hemispherical shell of incremental thickness $\delta \mathrm{r}$ is given by:

$\frac{V}{\delta r}=-\rho \cdot j$

The current density (j) is the current (I) divided by the area over which the current is distributed (for a hemisphere, the area is $2 \pi r^{2}$ ) so that the above equation becomes

$\frac{V}{\delta r}=-\rho \frac{I}{2 \pi r^{2}}$

Thus the voltage $\mathrm{V}_{\mathrm{r}}$ at a point $\mathrm{r}$ from the current point source is:

$V_{r}=\int V=-\int \rho \cdot \frac{I \delta r}{2 \pi r^{2}}=\frac{\rho I}{2 \pi} \cdot \frac{1}{r}$

For a current source and sink, the potential $V_{P}$ at any point $P$ in the ground is equal to the sum of the voltage from the two electrodes, such that: $V_{P}=V_{A}+V_{B}$ where $V_{A}$ and $V_{B}$ are the potential contributions from the two electrodes, $A(+I)$ and $B(-I)$. The potentials at electrode $\mathrm{M}$ and $\mathrm{N}$ are:

$V_{M}=\frac{\rho I}{2 \pi}\left[\frac{1}{A M}-\frac{1}{M B}\right]$

$V_{N}=\frac{\rho I}{2 \pi}\left[\frac{1}{A N}-\frac{1}{N B}\right]$

The potential difference $(\delta \mathrm{V})$ is given by;

$\delta V_{M N}=V_{M}-V_{N}$

$\delta V_{M N}=\frac{\rho I}{2 \pi}\left\{\left[\frac{1}{A M}-\frac{1}{M B}\right]-\left[\frac{1}{A N}-\frac{1}{N B}\right]\right\}$

Solving and making the resistivity $\rho$ the subject we have

$\rho=2 \pi \frac{\delta V_{M N}}{I}\left\{\left[\frac{1}{A M}-\frac{1}{M B}\right]-\left[\frac{1}{A N}-\frac{1}{N B}\right]\right\}^{-1}$

$\boldsymbol{K}=2 \pi\left\{\left[\frac{1}{A M}-\frac{1}{M B}\right]-\left[\frac{1}{A N}-\frac{1}{N B}\right]\right\}^{-1}$

Which is the geometric factor depending on the arrangement of the four electrodes.

For Wenner-Schlumber configuration, $\mathrm{AM}=n a,=n a+a, A N=n a+a$, and $N B=n a$

Substituting these into eqn. (11) we have 
International Journal of Advances in Scientific Research and Engineering (ijasre), Vol 6 (6), June -2020

$$
\begin{gathered}
\boldsymbol{K}=2 \pi\left\{\left[\frac{1}{n a}-\frac{1}{n a+a}\right]-\left[\frac{1}{n a+a}-\frac{1}{n a}\right]\right\}^{-1} \\
\boldsymbol{K}=2 \pi\left\{\left[\frac{n a+a-n a}{n a(n a+a)}\right]-\left[\frac{n a-(n a+a)}{n a(n a+a)}\right]\right\}^{-1} \\
\boldsymbol{K}=2 \pi\left\{\left[\frac{a}{n a(n a+a)}\right]-\left[\frac{-a}{n a(n a+a)}\right]\right\}^{-1} \\
\boldsymbol{K}=2 \pi\left\{\left[\frac{2}{n a(n+1)}\right]\right\}^{-1}
\end{gathered}
$$

$K=2 \pi\left(\frac{n a(n+1)}{2}\right)=\pi n a(n+1)$

From Ohm's law, $\boldsymbol{R}=\frac{\delta V_{M N}}{I}$, equation (8) reduces to

$\rho=K R$

Where $\mathbf{K}$ is the geometric factor which depends on the arrangement of the four electrodes.

Where the ground is not uniform, the resistivity so calculated is called the apparent resistivity ( $\rho$ a) because these measurements are made over a real heterogeneous earth, as distinguished from the fictitious homogenous half-space, the symbol $\boldsymbol{\rho}$ is replaced by $\boldsymbol{\rho}_{\mathbf{a}}$ for apparent resistivity.

$\rho_{a}=K R$

14

\section{Methods}

For this research work, data was acquired using Petrozenith earth resistivity meter.

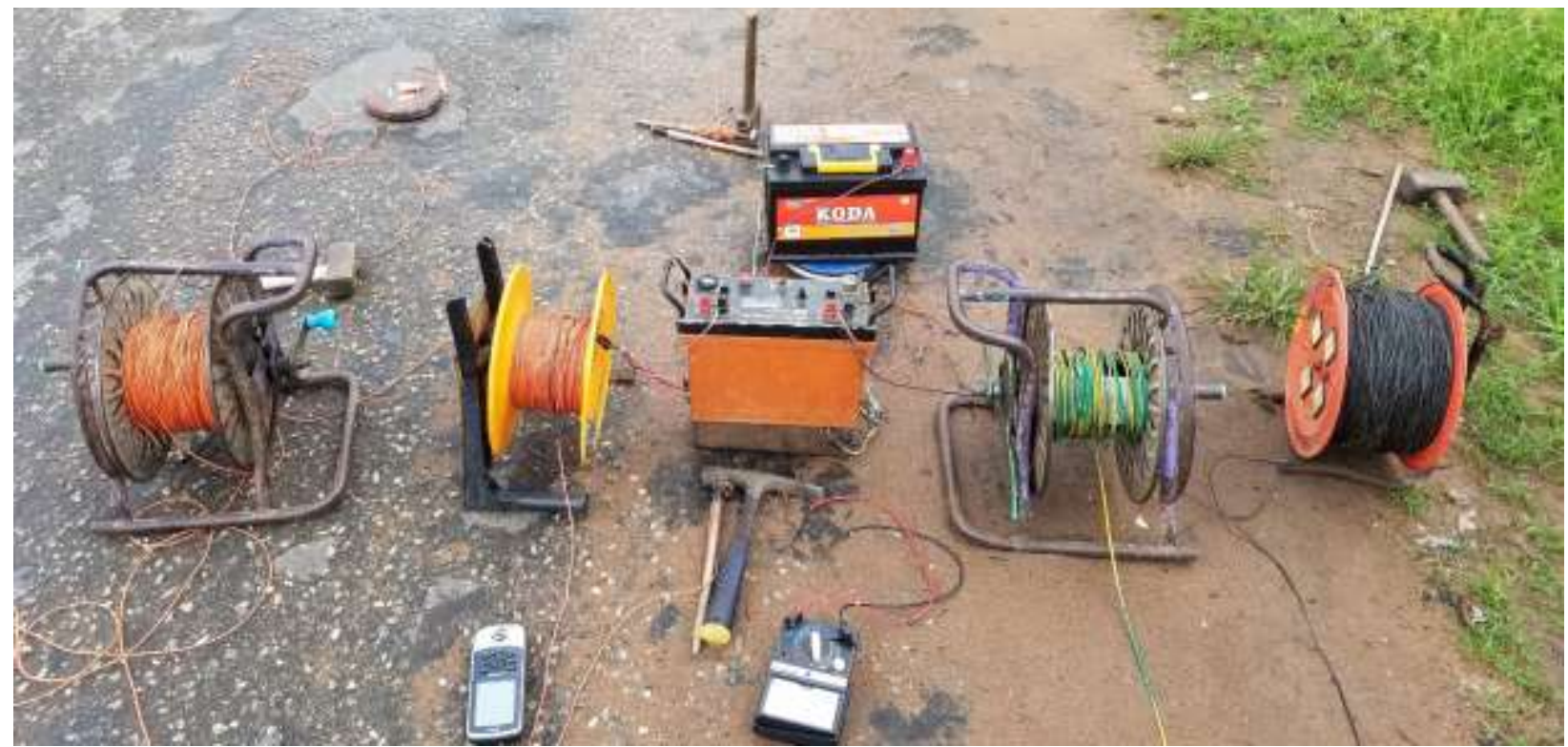

Figure 1: Petrozenith Earth Resistivity Meter Setup.

The electrical resistivity technique employed is the Wenner-Schlumberger hybrid configuration. Wenner-Schlumberger technique is a configuration with a constant system of spacing rules with a note of factor " $\mathrm{n}$ " as this configuration is the comparison of the distance between C1-P1 (or C2-P2) electrodes with spaces between P1-P2 as in figure 2. If the distance between electrodes. The potentials (P1 and P2) are 'a' than the distance between the current electrode (C1 and C2) is 2na $+\mathrm{a}$ [13]. 
This procedure utilizes 4 electrodes placed in a straight line and combines both the Wenner and Schlumberger configuration for determining the resistance offered by the subsurface. For the particular measurement for which the spacing factor ' $n$ 'is equal to 1 , this technique takes the form of measurement in the Wenner configuration but for measurements for $\mathrm{n}=2,3,4$ and so on, then Wenner-Schlumberger technique is the same as the Schlumberger configuration. The current electrode and the potential electrode are greater than the distance between the potential electrodes.

Using this technique, data were acquired and the resistivity imaging were interpreted geologically using the standard resistivity values for rocks, minerals and sediments from available literatures and also using the knowledge of the local geology of the research area. Table 1 shows some earth materials and their respective resistivity.

Table 1: Electrical Resistivity of Some Earth Material [14].

\begin{tabular}{|l|l|}
\hline ROCK MATERIAL & RESISTIVITY (Ohm-meter) \\
\hline Top soil & $50-1,000$ \\
\hline Alluvium & $25-1,500$ \\
\hline Syenite & $100-100,000$ \\
\hline Gnesis & $200-34,000$ \\
\hline Granite & $300-20,000$ \\
\hline Basalt & $200-20,000$ \\
\hline Marble & $100-200,000$ \\
\hline Quartzite & $10-200,000$ \\
\hline Gabbio & 15,000 \\
\hline Schist & $50-10,000$ \\
\hline Biorite & 50,000 \\
\hline Shale & $80-20,000$ \\
\hline Sandstone & $30-500,000$ \\
\hline Clay-shale & $0.00004-900$ \\
\hline Limestone & $30-500,000$ \\
\hline Clay & $1-100$ \\
\hline Fresh Groundwater & $10-100$ \\
\hline Loams & $10-450$ \\
\hline Sand & $100-500,000$ \\
\hline Marl & $50-90$ \\
\hline Oil Sands & $60-900$ \\
\hline & \\
\hline
\end{tabular}

\section{RESULTS AND DISCUSSION}

Geoelectrical investigation of the subsurface was carried out. The resistance offered by the subsurface materials was measured by the Petrozenith earth resistivity meter by appropriately measuring the electrical potential (V) resulting from the current input (I) into the ground and from Ohm's law $R=\frac{V}{I}$ the resistance values was recorded. The apparent resistivity $\rho_{a}$ was computed using the equation, $\rho_{a}=K R$

Two locations were investigated in the study area each of $200 \mathrm{~m}$ in length and data were collected. Res2dinv software was used to process the data. Geoelectric imaging consisting of three figures was obtained. The upper modeled with the raw apparent resistivity. The middle represents model of the computer generated apparent resistivity data. These two figures are termed pseudosection. The lower figure is produced with the inverted apparent resistivity data, which is the true subsurface resistivity. This lower figure is what is used to deduce the geological characteristics of the surveyed depth range. The result obtained from each of these survey lines are presented in Tables 2 and 3. 
International Journal of Advances in Scientific Research and Engineering (ijasre), Vol 6 (6), June -2020

TRAVERSE 3: BEGIN, LAT. 0604'27.5" LONG. 05³9'18.6" Elev. 18.4m

END, LAT. 06 04'27.4" LONG. 05³9'12.2" Elev. 21.7m

LOCATION : OZOLUA GRAMMAR SCHOOL, OLOGBO, EDO STATE

SURVEY DATE: $\quad 24 / 10 / 2018$

Table 2: Resistivity Data for Traverse 3

\begin{tabular}{|c|c|c|c|c|c|}
\hline \multicolumn{6}{|c|}{ Electrode Location $a=10, n=1, k=62.84$} \\
\hline $\mathrm{C} 1$ & P1 & P2 & $\mathrm{C} 2$ & $\mathrm{R}(\Omega)$ & $\rho(\Omega \mathrm{m})$ \\
\hline 0 & 10 & 20 & 30 & 2.7 & 1866 \\
\hline 10 & 20 & 30 & 40 & 11.27 & 2432 \\
\hline 20 & 30 & 40 & 50 & 8.65 & 2294 \\
\hline 30 & 40 & 50 & 60 & 9.62 & 1546 \\
\hline 40 & 50 & 60 & 70 & 7.71 & 2551 \\
\hline 50 & 60 & 70 & 80 & 10.45 & 727 \\
\hline 60 & 70 & 80 & 90 & 2.32 & 2105 \\
\hline 70 & 80 & 90 & 100 & 14.64 & 1734 \\
\hline 80 & 90 & 100 & 110 & 12.51 & 1678 \\
\hline 90 & 100 & 110 & 120 & 11.27 & 281 \\
\hline 100 & 110 & 120 & 130 & 10.98 & 302 \\
\hline 110 & 120 & 130 & 140 & 9.7 & 311 \\
\hline 120 & 130 & 140 & 150 & 7.35 & 357 \\
\hline 130 & 140 & 150 & 160 & 7.73 & 310 \\
\hline 140 & 150 & 160 & 170 & 6.31 & 383 \\
\hline 150 & 160 & 170 & 180 & 6.22 & 451 \\
\hline 160 & 170 & 180 & 190 & 24.8 & 364 \\
\hline 170 & 180 & 190 & 200 & 24.2 & 1571 \\
\hline \multicolumn{6}{|c|}{ Electrode Location a $=10, n=2, k=125.68$} \\
\hline 0 & 20 & 40 & 60 & 0.422 & 1847 \\
\hline 10 & 30 & 50 & 70 & 15.33 & 1443 \\
\hline
\end{tabular}


International Journal of Advances in Scientific Research and Engineering (ijasre), Vol 6 (6), June -2020

\begin{tabular}{|c|c|c|c|c|c|}
\hline 20 & 40 & 60 & 80 & 15.65 & 1714 \\
\hline 30 & 50 & 70 & 90 & 15.44 & 2174 \\
\hline 40 & 60 & 80 & 100 & 15.56 & 1673 \\
\hline 50 & 70 & 90 & 110 & 17.78 & 1359 \\
\hline 60 & 80 & 100 & 120 & 17.91 & 1565 \\
\hline 70 & 90 & 110 & 130 & 15.82 & 1381 \\
\hline 80 & 100 & 120 & 140 & 16.04 & 1279 \\
\hline 90 & 110 & 130 & 150 & 17.27 & 1340 \\
\hline 100 & 120 & 140 & 160 & 15.49 & 1262 \\
\hline 110 & 130 & 150 & 170 & 12.49 & 1235 \\
\hline 120 & 140 & 160 & 180 & 13.52 & 1284 \\
\hline 130 & 150 & 170 & 190 & 12.66 & 1150 \\
\hline 140 & 160 & 180 & 200 & 11.28 & 1278 \\
\hline \multicolumn{6}{|c|}{ Electrode Location a $=10, n=3, k=188.52$} \\
\hline 0 & 30 & 60 & 90 & 2.02 & 1182 \\
\hline 10 & 40 & 70 & 100 & 8.47 & 1382 \\
\hline 20 & 50 & 80 & 110 & 8.83 & 1621 \\
\hline 30 & 60 & 90 & 120 & 11.5 & 1484 \\
\hline 40 & 70 & 100 & 130 & 9.71 & 1354 \\
\hline 50 & 80 & 110 & 140 & 9.16 & 1193 \\
\hline 60 & 90 & 120 & 150 & 9.15 & 1278 \\
\hline 70 & 100 & 130 & 160 & 8.69 & 1037 \\
\hline 80 & 110 & 140 & 170 & 8.35 & 1248 \\
\hline 90 & 120 & 150 & 180 & 6.95 & 1171 \\
\hline 100 & 130 & 160 & 190 & 6.97 & 1129 \\
\hline 110 & 140 & 170 & 200 & 7.42 & 1037 \\
\hline \multicolumn{6}{|c|}{ Electrode Location $a=10, n=4, k=251.36$} \\
\hline 0 & 40 & 80 & 120 & 3.73 & 993 \\
\hline 10 & 50 & 90 & 130 & 5.74 & 1430 \\
\hline 20 & 60 & 100 & 140 & 6.24 & 1493 \\
\hline 30 & 70 & 110 & 150 & 6.5 & 1312 \\
\hline 40 & 80 & 120 & 160 & 6.14 & 1264 \\
\hline 50 & 90 & 130 & 170 & 6.01 & 1217 \\
\hline 60 & 100 & 140 & 180 & 5.72 & 1259 \\
\hline 70 & 110 & 150 & 190 & 5.64 & 1051 \\
\hline 80 & 120 & 160 & 200 & 5.48 & 1108 \\
\hline \multicolumn{6}{|c|}{ Electrode Location a $=10, n=5, k=314.2$} \\
\hline 0 & 50 & 100 & 150 & 0.121 & 1078 \\
\hline 10 & 60 & 110 & 160 & 3.89 & 1332 \\
\hline 20 & 70 & 120 & 170 & 4.59 & 1379 \\
\hline 30 & 80 & 130 & 180 & 4.85 & 1329 \\
\hline 40 & 90 & 140 & 190 & 4.23 & 1244 \\
\hline 50 & 100 & 150 & 200 & 4.5 & 1093 \\
\hline
\end{tabular}


International Journal of Advances in Scientific Research and Engineering (ijasre), Vol 6 (6), June -2020

TRAVERSE 8: BEGIN, LAT. 0604'49.6" LONG. 05³9'41.9" Elev. 22.4m END, LAT. 06 04' '56.1" LONG. 05³9’ 41.8" Elev. 28.2m

LOCATION: Imasabor Road, Ologbo, Edo State. SURVEY DATE: $26 / 10 / 2018$

Table 3: Resistivity Data fo

\begin{tabular}{|c|c|c|c|c|c|}
\hline \multicolumn{6}{|c|}{ Electrode Location $a=10, n=1, k=62.84$} \\
\hline $\mathrm{C} 1$ & $\mathrm{P} 1$ & $\mathrm{P} 2$ & $\mathrm{C} 2$ & $\mathrm{R}(\Omega)$ & $\rho(\Omega \mathrm{m})$ \\
\hline 0 & 10 & 20 & 30 & 2.7 & 635 \\
\hline 10 & 20 & 30 & 40 & 11.27 & 585 \\
\hline 20 & 30 & 40 & 50 & 8.65 & 498 \\
\hline 30 & 40 & 50 & 60 & 9.62 & 452 \\
\hline 40 & 50 & 60 & 70 & 7.71 & 476 \\
\hline 50 & 60 & 70 & 80 & 10.45 & 586 \\
\hline 60 & 70 & 80 & 90 & 2.32 & 524 \\
\hline 70 & 80 & 90 & 100 & 14.64 & 588 \\
\hline 80 & 90 & 100 & 110 & 12.51 & 796 \\
\hline 90 & 100 & 110 & 120 & 11.27 & 882 \\
\hline 100 & 110 & 120 & 130 & 10.98 & 1042 \\
\hline 110 & 120 & 130 & 140 & 9.7 & 1208 \\
\hline 120 & 130 & 140 & 150 & 7.35 & 1022 \\
\hline 130 & 140 & 150 & 160 & 7.73 & 1019 \\
\hline 140 & 150 & 160 & 170 & 6.31 & 1021 \\
\hline 150 & 160 & 170 & 180 & 6.22 & 876 \\
\hline 160 & 170 & 180 & 190 & 24.8 & 887 \\
\hline 170 & 180 & 190 & 200 & 24.2 & 803 \\
\hline \multicolumn{6}{|c|}{ Electrode Location $a=10, n=2, k=125.68$} \\
\hline 0 & 20 & 40 & 60 & 0.422 & 1065 \\
\hline 10 & 30 & 50 & 70 & 15.33 & 743 \\
\hline 20 & 40 & 60 & 80 & 15.65 & 613 \\
\hline 30 & 50 & 70 & 90 & 15.44 & 682 \\
\hline 40 & 60 & 80 & 100 & 15.56 & 659 \\
\hline 50 & 70 & 90 & 110 & 17.78 & 720 \\
\hline 60 & 80 & 100 & 120 & 17.91 & 900 \\
\hline 70 & 90 & 110 & 130 & 15.82 & 1075 \\
\hline 80 & 100 & 120 & 140 & 16.04 & 1027 \\
\hline 90 & 110 & 130 & 150 & 17.27 & 1208 \\
\hline 100 & 120 & 140 & 160 & 15.49 & 1230 \\
\hline 110 & 130 & 150 & 170 & 12.49 & 1117 \\
\hline 120 & 140 & 160 & 180 & 13.52 & 1127 \\
\hline 130 & 150 & 170 & 190 & 12.66 & 1115 \\
\hline 140 & 160 & 180 & 200 & 11.28 & 1061 \\
\hline \multicolumn{6}{|c|}{ Electrode Location $a=10, n=3, k=188.52$} \\
\hline 0 & 30 & 60 & 90 & 2.02 & 649 \\
\hline 10 & 40 & 70 & 100 & 8.47 & 818 \\
\hline
\end{tabular}


International Journal of Advances in Scientific Research and Engineering (ijasre), Vol 6 (6), June -2020

\begin{tabular}{|c|c|c|c|c|c|}
\hline 20 & 50 & 80 & 110 & 8.83 & 892 \\
\hline 30 & 60 & 90 & 120 & 11.5 & 956 \\
\hline 40 & 70 & 100 & 130 & 9.71 & 924 \\
\hline 50 & 80 & 110 & 140 & 9.16 & 1039 \\
\hline 60 & 90 & 120 & 150 & 9.15 & 1101 \\
\hline 70 & 100 & 130 & 160 & 8.69 & 1393 \\
\hline 80 & 110 & 140 & 170 & 8.35 & 1231 \\
\hline 90 & 120 & 150 & 180 & 6.95 & 1097 \\
\hline 100 & 130 & 160 & 190 & 6.97 & 1114 \\
\hline 110 & 140 & 170 & 200 & 7.42 & 1214 \\
\hline \multicolumn{6}{|c|}{ Electrode Location a $=10, n=4, k=251.36$} \\
\hline 0 & 40 & 80 & 120 & 3.73 & 980 \\
\hline 10 & 50 & 90 & 130 & 5.74 & 1481 \\
\hline 20 & 60 & 100 & 140 & 6.24 & 1217 \\
\hline 30 & 70 & 110 & 150 & 6.5 & 1239 \\
\hline 40 & 80 & 120 & 160 & 6.14 & 1156 \\
\hline 50 & 90 & 130 & 170 & 6.01 & 1322 \\
\hline 60 & 100 & 140 & 180 & 5.72 & 1403 \\
\hline 70 & 110 & 150 & 190 & 5.64 & 1428 \\
\hline 80 & 120 & 160 & 200 & 5.48 & 1224 \\
\hline \multicolumn{6}{|c|}{ Electrode Location $a=10, n=5, k=314.2$} \\
\hline 0 & 50 & 100 & 150 & 0.121 & 1043 \\
\hline 10 & 60 & 110 & 160 & 3.89 & 2196 \\
\hline 20 & 70 & 120 & 170 & 4.59 & 1618 \\
\hline 30 & 80 & 130 & 180 & 4.85 & 1351 \\
\hline 40 & 90 & 140 & 190 & 4.23 & 1323 \\
\hline 50 & 100 & 150 & 200 & 4.5 & 1213 \\
\hline
\end{tabular}

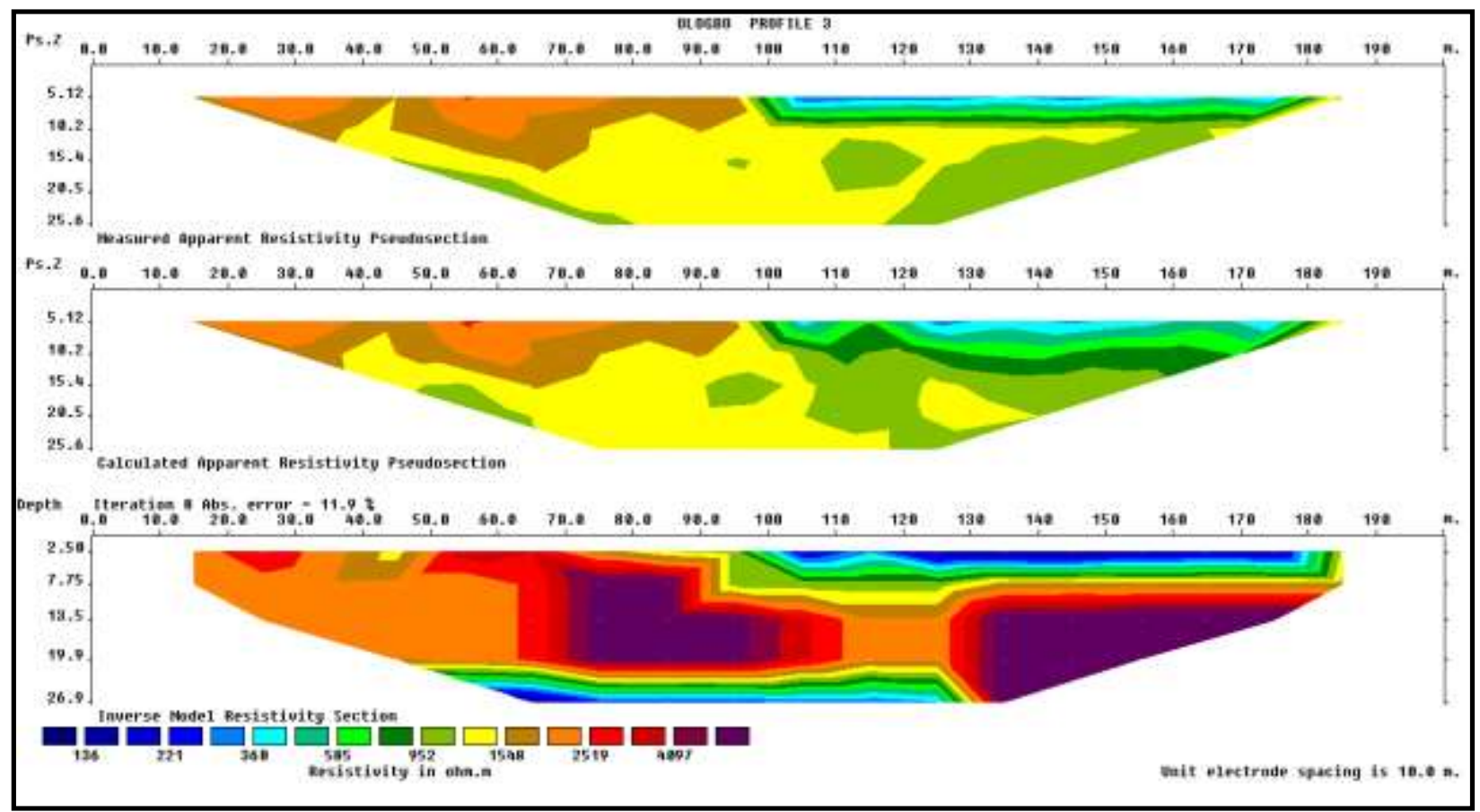

Figure 3: Resistivity Imaging Of Profile 3 
International Journal of Advances in Scientific Research and Engineering (ijasre), Vol 6 (6), June -2020

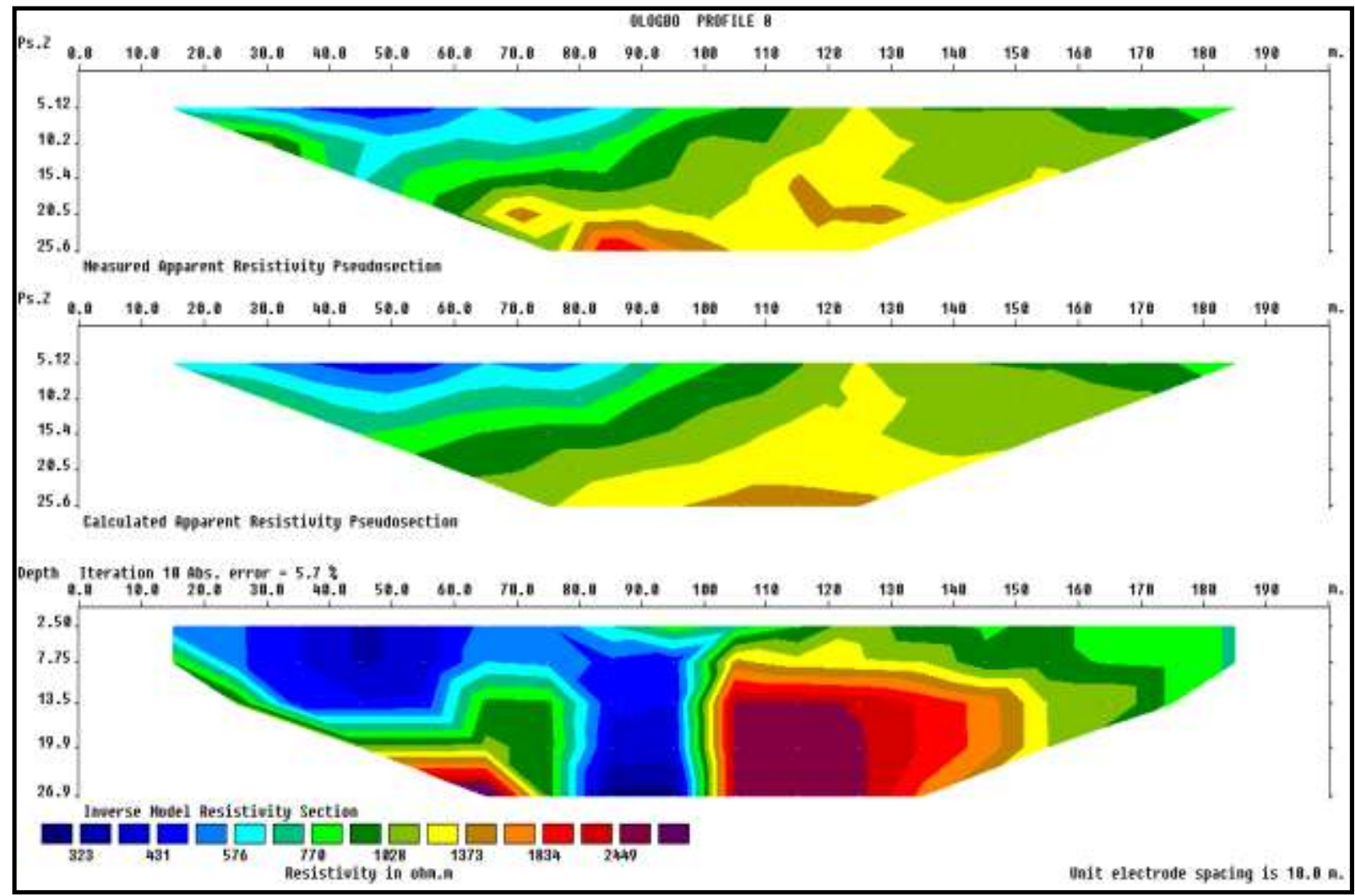

Figure 4: Resistivity Imaging Of Profile 8

\section{INTERPRETATION}

The resistivity imaging representing the variation of resistivity with depth along profile 3 is shown in figure 3 . The low resistive material with apparent resistivity values $136-360 \Omega \mathrm{m}$ is interpreted to be clayey-sand Formation. This Formation spreads laterally from $105 \mathrm{~m}-180 \mathrm{~m}$ along the profile with a depth of about $3 \mathrm{~m}$. Underlain by this clayey-sand Formation are layers with apparent resistivity between $360-1548 \Omega \mathrm{m}$ which depicts a lateritic soil Formation. Sections with apparent resistivity values between $1548-2519 \Omega \mathrm{m}$ is interpreted to be lateritic sand Formation which occurs between $15 \mathrm{~m}-63 \mathrm{~m}$ and $110 \mathrm{~m}-128 \mathrm{~m}$ along the profile with depth penetration of about $20 \mathrm{~m}$. Enclosed is a high resistive zone of apparent resistivity of above $4097 \Omega \mathrm{m}$ which is interpreted to be sandstone and occurs at a depth of about $5 \mathrm{~m}-19.9 \mathrm{~m}$ with lateral extent from $70 \mathrm{~m}-100 \mathrm{~m}$ along the profile. This high resistive zone is also seen along the profile from $130 \mathrm{~m}$ beyond the extent of investigation and at depth of about $11 \mathrm{~m}$ beyond the depth of investigation.

The resistivity imaging for profile 8 which shows the variation of resistivity along the profile with depth is shown in figure 4 above. Along the profile, there is a section of low resistive material which ranges from $323 \Omega \mathrm{m}$ to $576 \Omega \mathrm{m}$ suggestive of lateritic clay. This section has a lateral extension from $15 \mathrm{~m}$ to $70 \mathrm{~m}$ along the profile with a depth of about $14.5 \mathrm{~m}$ which consists of four moderately consistent layers. This low resistivity section is also seen from $80 \mathrm{~m}$ to $100 \mathrm{~m}$ along the profile which extends downward beyond the depth of investigation. Below this laterite clay is underlain by layers with apparent resistivity value of range $576 \Omega \mathrm{m}$ to $1028 \Omega \mathrm{m}$ spreading from $15 \mathrm{~m}$ to $80 \mathrm{~m}$ and also seen between $98 \mathrm{~m}$ to $180 \mathrm{~m}$ along the profile which indicates the presence of lateritic material Underlain this are four layers with apparent resistivity values ranging from $1028 \Omega \mathrm{m}-1373 \Omega \mathrm{m}$ interpreted to be lateritic sand. Layers with resistivity values with range from $1373 \Omega \mathrm{m}-1834 \Omega \mathrm{m}$ is interpreted to be wet sand. Layers with resistivity values which ranges from $1834 \Omega \mathrm{m}-2449 \Omega \mathrm{m}$ and above is interpreted to be dry sand. The last layer which is composed of a high resistive zone with apparent resistivity value of $2449 \Omega \mathrm{m}$ and above indicates the presence of sandstone. This appears like a dome-like structure which extends beyond the depth of investigation. 


\section{CONCLUSION}

This study was carried out using Wenner - Schlumberger configuration of electrical resistivity method to characterize the lithostratigraphy of the subsurface in the study location. Res2dinv software was used to process the data from each of the surveyed profile. Geoelectric imaging consisting of three figures were obtained and are interpreted to generate the subsurface geologic characteristics.

The analysis and interpretation of the results shows the presence of clayey sand, lateritic clay, laterite, sand and sandstone as the make-up of the subsurface of the study area. The litghostratigrafic units are predominantly sandy and lateritic.

\section{REFERENCES}

1. Adekunle, A., Ekandem, E. S., Ibe, k., Ananso, G.N., Mondigha, E.B., (2014). Analysis of thermal and electrical properties of laterite, clay and sand samples and their effect on inhabited buildings in Ota, Ogun State, Nigeria. Journal of Sustainable Development Studies, ISSN 22014268, Volume 6, Number 2, 391-412.

2. Suzanne Christine Aboudi Mana, Marlia Mohd Hanafiah and Ahmed Jala Khan Chowdhury (2017) Environmental characteristics of clay and clay-based minerals, Geology, Ecology, and Landscapes, 1;3, 155-161, DOI: 10.1080/24749508.2017.1361128

3. Ezomo, F.O and Ifedili, S.O., (2005). Determination of water bearing formations at Osasogie Quarters by electrical Resistivity method. Journal of civil and Environ. Systems Engr. 6(1), 1-12.

4. Abanum C. Bright.; Two-dimensional electrical imaging techniques for determination of groundwater potential in edo state, Nigeria, International journal of modern applied physics, 10(1), (2020): 1-15

5. A. Mangeney, et al, A numerical study of anisotropic, low Reynolds number, free surface flow for ice sheet modeling, (Journal of Geophysical Research: Solid Earth, 1997), pp. 22749-22764

6. Akpokodje, E.U, \& Etu-Efeotor, J.O (1987). The occurrence and economic potential of clean sand deposits of the Niger Delta. Journal of African Earth Sciences, Vol. 6 (1), pp. 61 - 65.

7. Aisabokhae J.E., Adagbon J.E (2016). Geophysical Determination of Construction Clay Deposit Using 2-Dimensional Resistivity Imaging In Ologbo Area of Edo State. Research \& Reviews: Journal of Physics. 5(2): 1-12p.

8. Ozegin, K.O., Ataman, O.J. and Jegede, S.I. (2017). Dumpsite Characterization in Ekpoma from Integrated Surface Geophysical Methods. Physical Science International Journal. 15 (4). 1-11.

9. Sørensen K.I, Auken E, Christensen NB, Pellerin L 2005 J. Society of Exploration Geophysics $13585-603$.

10. Kizlo, M., and Kanbergs, A. (2009). The Causes of the Parameters Changes of Soil Resistivity. The 50 ${ }^{\text {th }}$ International Scientific Conference, Power and Electrical Engineering, 43-46.

11. Agogo, G.E: The electrical resistivity $\log$ as an aid in determining some reservoir characteristics. Petroleum Trans. A.I.M.E. 2009; 46:54-62.

12. Ezomo, F.O., Justice .E. Adagbon, Ojeabu Akhirevbulu, and Ezekiel Abriku (2015). Delineation of Subsurface Lithology using Two- Dimensional Geoelectrical Resistivity Imaging in Ologbo Area of Edo State, Nigeria. International Journal of Scientific and Engineering Research, 6(6):1110-1118.

13. Jamaluddin and Emi Prasetyawati Umar (2018). Identification of Subsurface Layer with Wenner-Schlumberger Arrays Configuration Geoelectrical Method. Global Colloquium on GeoSciences and Engineering. IOP Conf. Ser.: Earth Environ. Sci. 118012006.

14. Reynolds, J.M. (1997). An Introduction to Applied and Environmental Geophysics. John Willey and Sons Ltd., Chichester, UK, pp497. 